patients, who I am certain would unhesitatingly confide in him their innermost (and usually disreputable) secrets, knowing that they were stones that went to the bottom of a very deep pond. He achieved an equanimity in the face of human folly that I knew I should never be able to emulate."

I believe that this is a rare sighting of a Partridge in a Pare tree. Dr Daniels' description of a man of imperturbable wisdom reminds me of the College's motto "Let Wisdom Guide" and I would like to turn now to Dr Pare's connections with this College.

Dr Pare has been involved with the College in many different ways since its inception and had previously been involved with its predecessor, the RMPA. He was Secretary, and later Chairman, of the Programmes and Meetings Committee and did much to improve the scientific quality of Quarterly and Annual General Meetings and the standards of presentation at them. He followed this by being the Treasurer for seven years, from 1979 to 1986. Treasurers fall into two groups: the first are manic and spend as much money as they can; the second are depressed and hoard all they can, spending nothing. Dr Pare appears to have been able to both increase the value of the College's funds and extend its building without cutting back on normal expenditure. This I believe must be credited to his imperturbable temperament which has been mentioned earlier. Wisdom and probity are the qualities required of a Treasurer rather than fiscal ability or numeracy and Dr Pare had the necessary qualities in abundance. Dr Pare currently has the oversight of the College's Public Education Department.

The College Charter gives more than one reason for awarding an Honorary Fellowship. Firstly, for eminence in psychiatry or having rendered distinguished service in relation to the study, prevention and treatment of mental illness and also where someone has rendered notable service to the College. Dr Pare is very well qualified for the Honorary Fellowship for all of these reasons.

Professor Erik Strömgren (introduced by Professor E.S. Paykel)

Professor Strömgren is the doyen of Danish psychiatrists.
His father was Professor of Astronomy in Copenhagen (a post more recently held by his brother) and he was born in 1909 in the Royal Observatory, a beginning which may have contributed to his vision and wide perspective. He graduated from the University of Copenhagen Medical School and studied in Munich in the great research institute founded by Kraepelin.

From 1945 to 1980 he was Professor of Psychiatry in the University of Aarhus and Medical Superintendent of the Psychiatric Hospital in Risskov, in the grounds of which he gradually established a comprehensive and internationally famous research institute. He made major contributions to psychiatric genetics and to the use of stringent scientific methods in clinical psychiatric research. Genetics led to an interest in populations and to epidemiological studies on the islands of Bornholm and Samso on a grand scale.

He became Editor of the Acta Psychiatrica Scandinavica in 1953 and guided that excellent journal through some of its most distinguished years. His mastery of epidemiological data, his extensive knowledge of clinical psychiatry and his objective attitude to policy made him the main architect of the Mental Health Services in Denmark. He was Chairman of the World Psychiatric Association Section on Nomenclature and Classification from 1972-77. He has been widely influential in the development of ICD10 and prominent in many other activities in the World Health Organization. His wife, Lizzy Sand Strömgren, is a distinguished psychiatrist in her own right. Professor Strömgren is a man of wide culture, integrity and strength of purpose and has been honoured in all parts of the world for his contributions. He is an honorary member of psychiatric bodies in Denmark, Sweden and Germany, has been a recipient of the Ernst Carlsen Honorary Prize, the Norwegian Anders Jahre Prize, the Kraepelin Gold Medal, the Julius Wagner von Jauregg Medal. He was the Maudsley Lecturer of this College in 1985.

It is a privilege and a pleasure to present Professor Strömgren to you now for award of the Honorary Fellowship of our College.

\title{
Postgraduate psychiatry training at Keele
}

The Division of Psychiatry, Department of Postgraduate Medicine, is arranging the following postgraduate training programmes for the next academic year:

(1) Academic Psychiatry Foundation Course (Course Organiser: Dr K. Barrett). This course is designed with the requirements for MRCPsych Part I in mind.

(2) The Two Year Academic Course. This will assist in preparing trainees for MRCPsych Part II but will also assist trainees who are considering registering for the MSc Degree by thesis.
Advanced courses in puerperal mental illness, international and transcultural psychiatry are planned during the forthcoming academic year.

Further particulars and registration forms can be obtained from Mrs Norma Steele, Department of Postgraduate Medicine, University of Keele, Thornburrow Drive, Hartshill, Stoke on Trent ST4 7QB (telephone 0782 49144, Ext 4047). 